\title{
HACIENDO CAMINO AL CONTAR: REFLEXIONES SOBRE EL LIBRO HISTORIA DEL AUTISMO. CONVERSACIONES CON LOS PIONEROS (DE ADAM FEINSTEIN)
}

\section{Making Way when Counting. Reflections on the Book A History of Autism. Conversations with the Pioneers (by Adam Feinstein)}

Mercedes Belinchón Carmona

Universidad Autónoma de Madrid (UAM)

Facultad de Psicología. Departamento de Psicología Básica

Recepción: 27 de julio de 2020

Aceptación: 8 de octubre de 2020

Edición en español:
Historia del autismo. Conversaciones con los pioneros
Ávila, España: Autismo Ávila, 2016
463 páginas
ISBN: 978-84-940322-7-1
Traducción:
Mercedes Belinchón Carmona y Javier Muñoz Bravo
Edición original:
A History of Antism: Conversations with the Pioneers
Chichester, United Kingdom: Wiley-Blackwell, 2010
381 páginas
ISBN: 078-1-4051-8653-7
Edición en italiano:
Storia dell'autismo. Conversazioni con i pionieri
Traducción:
Barbara De Carli y equipo de redacción Uovonero
Crema, Italia: Uovonero, 2014
432 páginas
ISBN: 978-88-96918-20-3




\section{Antecedentes}

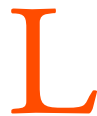

A PRIMERA VEZ QUE RECUERDo haber oído la palabra autismo fue durante un viaje en avión desde el aeropuerto londinense de Heathrow. Yo estaba hablando con un señor francés de aspecto distinguido, que estaba sentado a mi lado, sobre lo que más me preocupaba entonces: nuestro hijo de tres años de edad, Johnny, había dejado de hablar inexplicablemente y se mantenía apartado de sus compañeros de juegos. Mi vecino de asiento se giró hacia mí y me dijo: "Estoy bastante seguro de que su hijo tiene autismo”. Yo le escuché hablar educadamente y me guardé su tarjeta de visita, sin mirarla. Unos seis meses después, un equipo del Hospital St. George de Londres usó aquella misma palabra como diagnóstico para Johnny. Enseguida empecé a leer todo lo que podía encontrar sobre autismo y, algunos meses más tarde, le eché un vistazo a la tarjeta de visita que aún seguía en el bolsillo de mi chaqueta: el nombre que había en ella era el de Eric Fombonne, a quien ahora considero uno de los principales expertos del mundo sobre autismo (Feinstein, 2010, p. xxi de la ed. esp.).

Evocando esta anécdota personal, esencial en su vida y en la de su familia, inicia el escritor inglés Adam Feinstein (nacido en Cambridge) su Historia del autismo. Conversaciones con los pioneros, un libro cuyo título anticipa con exactitud tanto su contenido como su estructura y que, en mi opinión, debería formar parte de la biblioteca de cualquier persona e institución seriamente interesada en el amplio y complejo espectro de situaciones neuroevolutivas con que hoy en día se identifica el término 'autismo'. Confesaré que yo lo leí de tirón y con fruición en noviembre de 2010 mientras volaba hacia Monterrey para participar en el III Congreso Internacional de Autismo organizado en esa ciudad por la $\mathrm{OMA}^{1}$, si bien conocía el proyecto desde antes. Concretamente en abril de 2008, por mediación de M. ${ }^{a}$ Isabel Bayonas (presidenta entonces de $\mathrm{APNA}^{2}$ ), Feinstein y yo habíamos podido charlar larga y distendidamente, en la casa de Bayonas en Madrid, sobre Ángel Rivière y su trabajo pionero en el ámbito del autismo en España, asuntos ambos que Feinstein quería tratar de manera fidedigna en su libro. La tarde dio también para comentar anécdotas y datos curiosos sobre pioneros del autismo de otros países, de modo que, tras despedirnos, supe que ese libro contendría importantes novedades y que se alejaría del cansino relato 'estándar' sobre cómo, en la segunda mitad del siglo XX, el autismo se convirtió en un objeto específico de investigación y de atención profesional (me refiero a ese relato, repetido durante décadas, que comienza con un "El autismo fue descrito por primera vez en 1943 por Leo Kanner, un psiquiatra de origen austriaco emigrado a Estados Unidos que... etc., etc.” - para un análisis crítico de ese relato 'estándar', ver Belinchón, 2020 en prensa-).

En marzo de 2012, en unas Jornadas organizadas por Autismo-Burgos en esta ciudad, coincidí de nuevo con Feinstein y también con Gerardo Herrera (director de

Organización Mundial de Autismo, fundada en 1998 (https://worldautismorganisation.com/).

2 Actual Asociación de Padres de Personas con Autismo (antes Asociación de Padres de Niños con Autismo). Se fundó en 1976 y fue, como se explica en la Adenda del libro de Feinstein (ed. esp.), una de las asociaciones pioneras y más influyentes de España. Ángel Rivière colaboró como asesor técnico de esta asociación desde que esta se creó hasta que él falleció. 
la aún muy joven editorial Autismo Ávila y persona con la que desde tiempo atrás compartía mi interés por reconocer el papel de algunos pioneros y pioneras españoles del autismo). En ese encuentro en Burgos nos planteamos la posibilidad de preparar una edición del libro en castellano, con traducción mía del texto, que además ampliara lo dicho en la edición original sobre la historia del autismo en nuestro país. El proyecto arrancó pocos meses después, sumando para las tareas de traducción y de revisión de estilo las valiosas colaboraciones de mi colega en el Centro de Psicología Aplicada de la UAM Javier Muñoz Bravo y de Isabel Hoyos Seijo, colaboradora de la editorial Autismo Ávila. La edición se presentó en noviembre de 2016 en León, en el XVIII Congreso organizado por AETAPI, la Asociación Española de Profesionales del Autismo (http://aetapi.org/).

\section{Contexto (I)}

Si me he tomado la licencia de mencionar cómo contacté con este libro y con su autor no ha sido por razones personales, no. Estas (ateniéndome a las definiciones que proponen Grice, 1975, y Sperber y Wilson, 1986, para el término 'relevancia') las habría considerado totalmente 'irrelevantes' para esta reseña de no ser porque creo obligado ofrecer cierta justificación al hecho de escribir ahora estas páginas habiendo traducido el libro, una práctica inhabitual en el ámbito editorial. Suele ir de suyo, como argumento que desaconseja tal mezcolanza, que enfrentados a la tarea de hacer una reseña los traductores tienen difícil no sucumbir a sesgos, se supone que positivos, que serían incompatibles con un juicio crítico objetivo de las obras. Sin embargo, en descargo tanto mío como de los responsables de la revista Siglo Cero (a quienes aprovecho para agradecer haber aceptado este artículo), recurriré al contrargumento de que toda traducción no solo requiere buscar en la segunda lengua expresiones lingüísticas equivalentes a las frases del texto original, sino, sobre todo, ir más allá de este para interpretar e intentar entender qué pretendía expresar el autor al escribirlo. Este último proceso (sustentado psicológicamente, como todos los actos lingüísticos, en las capacidades de empatía y mentalización) diferencia radicalmente las traducciones humanas de las automáticas, generando solo en las primeras una conexión cómplice entre el texto, el autor y los traductores. Tal complicidad es cierto que sesga a priori el enjuiciamiento sobre la obra, pero también que en cierto modo lo facilita, porque ayuda a sobrevolar la literalidad del 'texto', a interpretarlo a la luz de su 'contexto' y a identificar sus 'subtextos' (i. e., sus contenidos implícitos). En el caso del libro que nos ocupa, tuve además el privilegio de haber podido comentar muchas de mis dudas sobre estos aspectos con el propio autor, en un diálogo que se mantiene abierto y que demuestra su generosidad intelectual.

En estas páginas me propongo comentar el texto, los contextos y algunos de los subtextos que a mi juicio contiene Historia del autismo. Conversaciones con los pioneros, obra publicada originalmente en inglés en 2010 (Ed. Wiley-Blackwell), en italiano en 2014 (Ed. Uovonero) y en español en 2016 (Ed. Autismo Ávila). En línea con lo narrado en la Adenda de la edición española, comentaré también algunos paralelismos 
que he creído detectar entre esta obra y ciertos aspectos de la persona y las obras de Ángel Rivière, pionero español destacado por Feinstein en su libro a quien rinden homenaje en el vigésimo aniversario de su fallecimiento este número de Siglo Cero y otras iniciativas (p. e., el número 43/4 que la revista Infancia y Aprendizaje/Journal of Psychology and Education publicará el próximo mes de noviembre, donde se analiza y actualiza críticamente la agenda teórica de este autor en el campo del autismo -ver Belinchón, Palomo y Campos, 2020, en prensa-). A modo de cierre, reproduciré las reflexiones que también muy generosamente me aportaron Adam Feinstein y Gerardo Herrera cuando les pedí su opinión sobre este libro al cumplirse diez y cuatro años, respectivamente, de la publicación de sus ediciones en inglés y en español. Precisamente por ser un libro de historia, este es un libro 'abierto' que admite reinterpretaciones, correcciones y compleciones en cada nueva lectura, dadas las nuevas informaciones que no han dejado de sucederse. Es por ello que consideré que nada podría cerrar mejor estas páginas que pulsar a través de la voz directa del autor y del editor responsable de su traducción al español cuán viva sigue la historia del autismo, qué rápidamente avanza, cómo la enriquecen distintas miradas y cuántos hilos narrativos se necesitaría escribir y reescribir aún para conocer todos los detalles de esa historia.

\section{Contexto (II)}

El libro Historia del autismo. Conversaciones con los pioneros es el fruto de un proyecto ambicioso, admirable y singular. Como se indica en su "Prólogo", el proyecto se inició en 2007 "con el objetivo de realizar un trabajo académico que recogiera lo fundamental de los últimos sesenta años, mientras lo ocurrido seguía vivo en la memoria [de sus protagonistas]" (ed. esp., p. xix, cursiva añadida).

El proyecto estuvo patrocinado por la Fundación Shirley, una fundación británica sin ánimo de lucro dedicada a la realización de proyectos estratégicos relacionados con los trastornos del espectro del autismo (http://shirleycharitablefoundation. org/). Se contó durante todo el proceso con el asesoramiento técnico de la Profa. Uta Frith, una de las más reputadas estudiosas del autismo en el mundo, aunque la cara más visible de este enorme esfuerzo colectivo es fundamentalmente el autor del libro: Adam Feinstein, un escritor y profesor inglés experto en poesía y cine que desde que conoció el diagnóstico de su hijo Johnny ha dedicado buena parte de su energía y curiosidad a promover iniciativas para mejorar la calidad de vida de las personas con trastornos de ese espectro y la de sus familiares, así como para intentar comprender el autismo y su historia.

Para escribir este libro, Feinstein viajó por más de cien países y entrevistó a casi trescientas personas durante más de tres años. También, incorporó en el texto comentarios de algunas entrevistas previas que había realizado antes de 2007 en distintos países para la revista internacional de autismo Looking Up, que él mismo dirige (http://www.lookingupautism.org/). Los entrevistados fueron los mismos padres y madres y los mismos investigadores que protagonizaron en su momento los hechos narrados, así como familiares y colaboradores cercanos de los pioneros ya fallecidos y 
personas responsables de servicios y/o de programas de investigación especializados. El autor recoge además el testimonio de varias personas autistas sin discapacidad intelectual que en su momento fueron pioneras en hablar públicamente sobre su autismo 'desde dentro' (concretamente, Temple Grandin, Donna Williams, Rose Blackburn y Wendy-ahora Wenn- Lawson) $)^{3,4}$.

\section{Texto}

El texto de esta historia del autismo se elaboró combinando múltiples fragmentos de esas entrevistas en una trama narrativa en la que formalmente predominan los testimonios en primera persona. Feinstein, además, añade al texto su propia 'voz', dirigiendo hábilmente sus preguntas hacia cuestiones centrales en la agenda de los principales estudios y servicios de autismo del mundo, y entreverando la evocación de los hechos pasados con el relato de sus propias opiniones, sus dudas y diversas anécdotas de sus viajes.

En un ejercicio realmente admirable de selección de temas de enorme significación histórica, teórica y práctica, ofrece Feinstein al lector un ágil y ameno mosaico polifónico en letra impresa, salpicado con su fino humor británico y con referencias (muchas de ellas sorprendentes y no pocas hilarantes) tanto sobre el contexto geopolítico, sociocultural y científico de los hechos narrados como sobre las situaciones concretas en que estos se rememoraron durante las entrevistas. Muchas de estas tuvieron lugar en los mismos domicilios y despachos que acogieron hace décadas algunas de las reuniones que cambiaron el rumbo de la historia del autismo (p. e., las que condujeron a decidir que la ahora muy prestigiosa asociación británica NAS ${ }^{5}$ ya se constituyera como una asociación específica de autismo, separada o no integrada en MENCAP, la asociación nacional fundada en 1946 por padres y madres con hijos con discapacidad intelectual y otros trastornos del desarrollo -ver pp. 95 y ss. de la ed. esp.-). Solo por la recuperación de esas voces y por la recreación que Feinstein hace de esos escenarios, el libro resulta impactante: muchos de los pioneros eran ya personas octogenarias o incluso nonagenarias cuando Feinstein las entrevistó, y de hecho varios

3 Empleo aquí deliberadamente la expresión 'personas autistas', en contra de ciertas normas de estilo, porque es así como piden que se les identifique muchas personas que están en el espectro del autismo y tienen alto nivel de funcionamiento, entre las que se incluyen las entrevistadas por Feinstein. Estas personas, como muchas otras, llevan años participando activamente en foros de autorrepresentación que demandan un reconocimiento y aceptación plenos de su 'neurodiversidad'. Como vislumbra Feinstein en el último capítulo del libro, la preferencia de estas personas por que se las llame 'autistas' y no 'personas con autismo o que han recibido diagnósticos de autismo’ no refleja un debate solo o principalmente nominal: es muestra de importantes cambios que han eclosionado en el siglo XXI y que conciernen tanto a la representación social del autismo como al modo en que las propias personas con este diagnóstico se representan a sí mismas dentro de la sociedad (ver Kennym et al., 2016).

4 Wendy Lawson es una persona transgénero. Junto con su pareja, ha tratado ampliamente esta cuestión en diversas publicaciones (ver, p. e., Lawson y Lawson, 2017).

5 National Autistic Society (https://www.autism.org.uk/). 
fallecieron antes de que vieran la luz la edición original del libro o sus traducciones, lo que concede a este texto un carácter único e irrepetible.

Formalmente, Historia del autismo. Conversaciones con los pioneros se compone de diez capítulos precedidos de un "Prólogo" de la presidenta de la Fundación Shirley y de una clarificadora "Introducción” del autor ${ }^{6}$. Todos los capítulos, ordenados de forma cronológica, ofrecen datos inéditos o poco conocidos que desmontan importantes piezas del relato tradicional 'estándar'. Por ejemplo, Feinstein confirma que las primeras descripciones de casos infantiles a los que se aplicó el calificativo 'autista' y que hoy recibirían un diagnóstico de $\mathrm{TEA}^{7}$ no fueron las que publicó Kanner en 1943, sino las descripciones de Víctor, el llamado ‘niño salvaje de Aveyron', escritas por el médico francés Jean-Marc Gaspard Itard a principios del siglo XIX, y sobre todo las que publicó la psiquiatra rusa Grunya Zhukareva en 1925, que se tradujeron en 1926 al alemán, lengua dominante en la literatura psiquiátrica hasta el último tercio del siglo XX (ver Zeldovich, 2019). Por otra parte, sostiene y justifica documentalmente Feinstein que el verdadero 'primer pionero' de la visión moderna sobre el autismo fue Hans Asperger y no Kanner, una defensa que ha resultado controvertida y se ha visto contaminada por las informaciones posteriores sobre la posible colaboración de Asperger con los nazis.

El libro rescata también del injusto olvido en el que los sumió el relato histórico 'estándar' (muy focalizado en lo hecho en el ámbito anglosajón) los nombres y contribuciones de numerosos profesionales e investigadores de distintos países y continentes sin cuyo reconocimiento la situación actual del autismo en todo el mundo sería simplemente ininteligible. Es el caso, por ejemplo, de Gerhard Bosch, psiquiatra alemán fallecido en 2011, que cuando fue entrevistado por Feinstein era "probablemente, a sus más de 90 años, el pionero vivo más anciano del planeta” (Feinstein, pp. 6-7 de la ed. esp.). Bosch fue uno de los primeros en diagnosticar en los años 1950 la psicopatía autista descrita por Asperger y en plantear, ya a principios de los años 60 , que ese trastorno y el autismo de Kanner probablemente no eran condiciones tan independientes entre sí como sostenían esos autores, anticipándose así, en más de medio siglo, a un debate que atraviesa distintos capítulos del libro y cuyo trasfondo teórico no puede darse por cerrado aún: el de cómo debería definirse el autismo para captar las singularidades comunes al conjunto del espectro reconociendo a la vez su extraordinaria diversidad (cada vez se están haciendo eco de este problema más autores, como puede verse en Fletcher-Watson y Happé, 2019). Por otro lado, en el libro se incluyen entrevistas cuyos interlocutores son personas de muy diversos países

6 CONTENIDOS: "Prólogo" de la Dama Stephanie Shirley. “Introducción”. 1. Los dos grandes pioneros. 2. La década de 1950: Las semillas del conocimiento. 3. La acusación a los padres. 4. La década de 1960: Los padres dan la batalla. 5. Los dos pioneros de la enseñanza. 6. La década de 1970: Pasos importantes. 7. Definición, diagnóstico y evaluación: Las herramientas y su historia. 8. Años 1980 y 1990: Conceptos y teorías. 9. El autismo en distintos países del mundo. 10. Dónde está el futuro. Adenda a la edición en español: Historia ampliada del autismo en España.

7 'Trastorno del Espectro del Autismo' es la etiqueta diagnóstica con la que tanto el DSM-5 como la CIE-11 identifican todas las formas de autismo clínicamente significativas (versus el patrón de funcionamiento llamado 'Fenotipo autista ampliado', presente en muchos padres y familiares de personas diagnosticadas de autismo, del que no derivan limitaciones funcionales ni necesidades de apoyo tan significativas). 
europeos, americanos, africanos, asiáticos y euroasiáticos (Rusia), lo que evidencia de paso hasta qué punto la versión 'estándar' de la historia del autismo es incompleta y parcial también desde el punto de vista étnico y cultural.

\section{Subtextos}

Historia del autismo. Conversaciones con los pioneros es, en primera instancia, un libro dirigido a reivindicar la contribución de los padres y madres de las personas con diagnósticos de autismo a la atención y la investigación especializadas. Desde su doble condición de padre de un hijo con ese diagnóstico y de estudioso de su historia, Feinstein documenta el papel ciertamente crucial de las familias, motor, según él, de que se haya reconocido la especificidad de las limitaciones y necesidades que provoca el TEA, y también de que en todo el mundo se haya producido un progreso exponencial en los programas de investigación y en los servicios especializados. La huella impresa en este libro de las 'voces' de tantos y tan diversos padres y madres pioneros resulta también sobrecogedora: revela angustia y dificultades de todo tipo en su vida cotidiana, paciencia, imaginación y también humor en su afrontamiento de los problemas, a la vez que refleja narrativas sorprendentemente compactas, ancladas muy sólidamente en valores y en conocimientos. Como muestra hábilmente Feinstein, esas narrativas se han ido ajustando a lo largo de este tiempo a las nuevas evidencias científicas y experienciales. También, se han irradiado capilarmente en los cinco continentes (aunque con ritmos distintos y especificidades), tanto en los microcontextos familiares como en los ámbitos vecinal, comunitario, institucional, político y mediático, desembocando en lo que ya hoy es una amplia y tupida trama asociativa de ámbito mundial cuya interdependencia con la labor de los profesionales, los investigadores y los académicos es inusualmente fuerte. Los dos exergos que elige Feinstein para su capítulo 4 (p. 84 de la ed. esp.) muestran a las claras lo inusual de esta interdependencia. En el primero, la reputada neuróloga estadounidense Mary Coleman (pionera en el reconocimiento, a principios de los años 1970, de la diversidad de causas y condiciones neurobiológicas que pueden provocar autismo) reconoce que "El autismo es un caso absolutamente único en la historia de la medicina, debido a las contribuciones tan importantes que han hecho los padres en este campo”. En el segundo, Ruth Sullivan (una madre pionera que fue la primera presidenta electa de la Autism Society of America) afirma: “Tengo la impresión de que, en todo el mundo, hay más pasión en las organizaciones dedicadas al autismo que en las de cualquier otra discapacidad”. Desde luego, si valiera como prueba indirecta de estas afirmaciones el crecimiento exponencial del número de publicaciones sobre autismo que aportan resultados originales de estudios en los que han colaborado las familias (p. e., Matson y LoVullo, 2009; Whyatt y Torres, 2018), bien podrían encontrarse razones adicionales para entender el a la vez cálido y firme homenaje que tributa Feinstein en este libro a las familias en su historia del autismo.

Con todo, siendo el anterior el leitmotiv (y por tanto el subtexto principal) de este libro, creo que Historia del autismo. Conversaciones con los pioneros no es en absoluto 
solo un libro de reconocimiento a esas familias (y a los y las investigadores/as que les acompañaron en su labor pionera aportando las evidencias científicas necesarias). Berend Verhoeff, psiquiatra y profesor de Teoría e Historia de la Psicología en la universidad holandesa de Groninga, en un artículo tan interesante como provocador, se refiere de pasada al libro de Feinstein como una historia del autismo "cuyo objeto son los pioneros en la atención, el tratamiento y la investigación” (2013a, p. 443), algo que, en mi opinión, en absoluto le hace justicia. Sin mencionar que tanto Feinstein como los autores de algunas otras monografías rigurosas sobre la historia del autismo son también padres o madres de personas con ese diagnóstico (p. e., Majia Holmer Nadesan, autora de un libro interesantísimo sobre las condiciones sociales y culturales que dieron lugar al autismo -Nadesan, 2005-), Verhoeff señalaba:

La mayoría de las historias del autismo han sido escritas por investigadores y expertos en autismo o por "historiadores profesionales", a menudo como un primer capítulo introductorio en textos y manuales, o como una breve introducción en artículos de revisión o estudios empíricos. Un denominador común a estas historias es que abordan su objeto principal, el autismo, como una "cosa” estática y descontextualizada que la ciencia puede descubrir. Además, estas historias presentan un desarrollo más o menos progresivo, cronológico y lineal hacia la "inevitable" interpretación actual del autismo, al tiempo que mencionan los mitos, errores, debates y convicciones científicamente erróneos de los períodos previos más oscuros. (Op. cit., p. 444)

El texto de Historia del autismo. Conversaciones con los pioneros, como ya dije, tiene ciertamente una organización cronológica y detalla cómo se fueron tejiendo los argumentos teóricos y empíricos que permitieron neutralizar mitos y convicciones 'erróneos' previos. Sin embargo, a mi juicio, si hay algo que no es la historia de Feinstein es precisamente una historia lineal y/o descontextualizada. Tampoco es en absoluto solo una historia sobre los pioneros. Y es que también es Verhoeff, como tantos otros autores antes, quien nos recuerda que revisar la historia de una disciplina nunca es un ejercicio accesorio o que distraiga del estudio de los asuntos que verdaderamente interesan a esta, sino que es una "parte central de la disciplina misma", porque es una actividad que legitima su objeto (Verhoeff, 2013a, p. 444).

Desde mi primera lectura del libro de Feinstein, confieso que este fue uno de los subtextos que me resultó más claro y también más sugerente: Historia del autismo. Conversaciones con los pioneros no solo cuenta las peripecias de estas personas, sino que esencialmente relata cómo a partir de los 1960 el autismo dejó de ser solo una situación clínica desconcertante para convertirse en un objeto de investigación institucionalizada por el que han acabado interesándose cada vez más disciplinas (Psiquiatría, Psicología, Neurociencias y otras). Para todas ellas, el autismo es ahora un desafío científico de primer orden, en la medida que muchos de los interrogantes que suscita y de las dificultades que entraña su estudio afectan al núcleo de sus propios objetivos disciplinares y a sus métodos de análisis de la realidad (piénsese, por ejemplo, en la dicotomía 'salud-enfermedad mental', tal como la han interpretado históricamente la Medicina y la Psiquiatría, o en la distinción entre funcionamiento o desarrollo psicológico ‘típico-no típico', 'normal-no normal', tan arraigada todavía en la Psicología 
y la Neuropsicología). En el libro de Feinstein se comprueba cómo estas y otras dicotomías sustentaron desde mediados del siglo XX un modo (rígidamente categorial) de hablar, de pensar y de actuar en relación con el autismo (un modo deudor de ese ideal de ciencia 'moderna', racional, positiva y objetiva que predominó durante buena parte de ese siglo). Pero, también, en el libro de Feinstein se hace evidente cómo ese zeitgeist (a la vez científico y cultural) comenzó a cambiar hacia los años 1980, debilitándose progresivamente desde entonces los criterios y límites de esas categorías, y abocando a planteamientos más laxos (p. e., dimensionales) a medida que se obtenían nuevos hallazgos científicos, se desarrollaban nuevas tecnologías y paradigmas de investigación y acontecían cambios culturales más amplios (ver Nadesan, 2005).

En ese mismo sentido, y en desacuerdo también con Verhoeff, yo diría que otro subtexto central en el libro de Feinstein (que difiere abiertamente de esas otras 'historias' escritas por los investigadores del autismo y los historiadores profesionales de que hablaba Verhoeff) es precisamente el que subraya la necesidad de situar o contextualizar el conocimiento de los hechos que posibilitaron el progreso de las teorías y de las prácticas sobre autismo desde los años 1960, demostrando cuán escasos han sido y son aún los textos académicos dedicados al análisis riguroso de los que los teóricos de la ciencia llaman "contexto de descubrimiento" y "contexto de justificación" .

El libro de Feinstein aporta mucha información novedosa sobre el 'contexto de descubrimiento' (particularmente datos biográficos y geopolíticos sobre los pioneros). No obstante, como advierten los autodenominados epistemólogos críticos, el 'contexto de justificación' de las teorías del autismo apenas ha sido estudiado (ver, entre las excepciones, Davidson y Orsini, 2010, y Verfoeff, 2012, 2013a, 2013b).

Dando un paso más allá en ese argumento, desde una perspectiva crítica podría interpretarse que las respuestas que comenzaron a darse en los años 1960 para neutralizar la acusación de que la causa del autismo era un inadecuado estilo parental incluían ya el germen de un programa investigador que naturaliza el autismo (i. e., que le concede el estatus ontológico de un fenómeno natural que solo se puede entender como resultado de alteraciones físicas en algunas áreas y/o mecanismos cerebrales). Ese 'marco' de análisis del autismo (en el sentido que le da al concepto de 'marco' Lakoff, 2004) parecería ser también el que acepta y legitima Feinstein en este libro. No obstante, la heterogeneidad de los países que visita y de los perfiles de las personas a las que entrevista permitirían suponer, a la vez, que él empatiza también con (o al menos no desdeña, como sí hacen los psiquiatras biologicistas y la mayoría de neurocientíficos) la idea ya 'postmoderna' de que el autismo, como cualquier otro objeto científico, se ha construido "material y discursivamente en contextos socioculturales específicos” (O’Dell et al., 2016, p. 167). Ninguna historia del autismo estará completa si obvia "los valores, las normas sociales y las diversas perspectivas sobre patología mental que juegan un rol significativo en [la definición de] 'eso que llamamos autismo’” (Verhoeff, 2013b, p. 1). La historia narrada por Feinstein contiene muchos

8 Según esta distinción clásica de Hans Reichenbach (1938/1952), el contexto de descubrimiento se refiere a la forma en que se generan nuevas ideas o hipótesis en ciencia; el contexto de justificación tiene que ver con el tipo de criterios que las hipótesis y teorías deben satisfacer para ser aceptadas en el corpus científico (para más detalles, ver en español Bárcenas, 2002). 
pasajes que apuntan en este sentido, aunque esta cuestión apenas se esboza y Feinstein no aclara su posición.

Por otro lado, creo que pueden identificarse también otros dos subtextos en este libro, que resulta mucho más liviano en su tono que en su fondo. Uno tiene que ver con poner en el centro de la historia del autismo a las personas, no al síndrome o la condición autista. Feinstein lo hace absolutamente en su libro al hacer recaer en los testimonios personales el grueso de su obra y al describir a todos los pioneros con gran detalle y empatía (salvo en aquellos pasajes que evidencian su animadversión por Bruno Bettelheim -compartida con la que también le profesaba Eric Schopler a este proponente de ideas y de prácticas que culpabilizaban cruelmente a los padres-y en los pasajes que traslucen también su nula simpatía por los métodos conductuales aversivos-punitivos que comenzó a aplicar Ivar Lovaas). Feinstein, de por sí una persona muy sensible, intenta en su libro entender y hacer entender lo que hicieron los distintos pioneros y por qué lo hicieron, y para ello aporta mucha información sobre sus respectivas circunstancias históricas y biográficas. Implícitamente, creo que así muestra también que, por muy asumido que esté que "nadie es imprescindible", la historia del autismo, como la de cualquier otro objeto científico o asunto, habría sido muy distinta con otros protagonistas.

Enredado con el anterior, y curiosamente, en cada nueva relectura de su libro atisbo con más claridad un último subtexto: aquel que reconoce el papel del azar, tanto en la vida de las personas como en la ciencia y en la escritura (a fin de cuentas, sobre lo que Feinstein escribe es sobre la vida y sobre la ciencia).

Sobre esto mismo, el afamado escritor ubetense Antonio Muñoz Molina escribió en 2012 que

Un buen argumento es aquel que permite ordenar materiales muy dispares de la imaginación y la experiencia en una sola composición unitaria. Pero la ciencia, y la simple observación de la vida, nos enseñan que no hay formas mejor organizadas ni más flexibles que las que suceden espontáneamente en la naturaleza, o en el azar de los hechos y los entrecruzamientos humanos.

Historia del autismo. Conversaciones con los pioneros no deja pasar ninguna oportunidad de mostrar cómo, en muchos de los hechos relatados y de su devenir, se dio un componente azaroso significativo. El azar, cuyo papel se obvia prescriptivamente en los textos académicos historicistas, hizo coincidir y vinculó a las diversas personas, instituciones y proyectos descritos en este libro, llevando muchas veces a elegir (como otras tantas a desestimar) líneas de investigación y proyectos que racionalmente o en un primer momento parecían promisorios. Ese subtexto sobre el papel del azar me lleva de nuevo, pero de otra manera, a la idea de que toda historia (y toda vida) es en última instancia un entrecruzamiento de azares tan único e irrepetible como únicas e irrepetibles son las vidas de sus protagonistas, aunque puedan encontrarse paralelismos entre algunos de ellos. 


\section{Paralelismos con Ángel Rivière}

Como no podía ser de otro modo, la figura del pionero español Ángel Rivière ocupa un lugar destacado en este libro de Feinstein (capítulo 4 de todas las ediciones y Adenda de la edición en castellano). También, como mencioné, el vigésimo aniversario del fallecimiento de Rivière ha propiciado volver a evocar colectivamente su recuerdo, confirmando una vez más cómo el respeto, la admiración y el cariño que en vida despertaba este autor siguen incólumes. No procede comentar aquí las razones concretas que justifican esas emociones (todas han sido destacadas ampliamente en los muchos homenajes hechos en su memoria -ver, p. e., Verdugo, Canal, Sotillo, Morueco y Tamarit, en este número de Siglo Cero-). Sin embargo, creo que sí pueden destacarse dos notas sobre los que, a mi modo de ver, podrían considerarse paralelismos entre Rivière, Feinstein y sus respectivas obras.

La primera nota me permite recordar que Rivière fue durante años profesor de Historia de la Psicología en las universidades Complutense y Autónoma de Madrid, siendo una característica muy destacada de su pensamiento que aplicaba al análisis de cualquier problema una lógica histórica rigurosa (como Feinstein hace también al contextualizar con gran precisión cada una de sus entrevistas tras su tono aparentemente desenfadado). Como alumna que fui de Rivière en esa materia cuando cursaba mis estudios de Psicología en la Complutense, puedo además dar cuenta de que una de las cosas que los y las estudiantes más valorábamos de sus clases era que su forma de explicar la Historia, como también es la de Feinstein en este libro, no era en absoluto rectilínea: Rivière, alejándose de la arraigada tradición escolástica que aún impregnaba la docencia universitaria en aquellos años (estoy hablando de la segunda mitad de los 1970), nos invitaba en sus clases a buscar conexiones entre hechos, datos e ideas asíncronos e incluso discordantes, y aprovechaba cualquier duda o intervención nuestra para buscar colaborativamente posibles interpretaciones alternativas, lo que lograba espolear nuestra curiosidad y provocó que nos interesáramos de por vida por una materia que quienes debieron cursarla con otros profesores consideraban letalmente aburrida (y perfectamente prescindible para su formación psicológica). Esa misma curiosidad intelectual por la historia la provoca ahora el libro de Feinstein, aparte de por las otras razones ya comentadas, porque, cuando combina en cada capítulo testimonios y experiencias disímiles (cosa que no es inhabitual), invita implícitamente al lector a buscar los criterios por los que en su momento el autor seleccionó y combinó los fragmentos de las entrevistas insertos en muchos pasajes.

Directamente relacionada con la anterior, una segunda nota me permite compartir la idea de que el de Feinstein es el primer libro traducido al español dedicado monográficamente a la historia del autismo, si bien, en rigor, Rivière fue quien por primera vez ofreció en esta lengua una narrativa sobre este trastorno expresamente anclada en la historia. Quizá porque fue la primera y porque además cubrió seria y eficazmente ese importante vacío previo, la narrativa "rivièriana" ha dejado una huella indeleble en quienes tuvimos el privilegio de poder conocerla de primera mano. Esa narrativa abarca el análisis de los rasgos clínicos del autismo, sus bases funcionales psicológicas y neurobiológicas, la complejidad de su diagnóstico y de las necesidades de apoyo 
de las personas que están en ese espectro y las de sus familiares; además, incardina las diversas preguntas y respuestas en el marco más general de las Ciencias del Comportamiento Humano y de la Vida (de las que forman parte también la Psicología Cognitiva y la Historia de la Psicología, materias ambas sobre las que Rivière pivotó casi toda su actividad académica). En consecuencia, y más allá de los contenidos concretos, de los sesgos (metateóricos, teóricos y metodológicos) o de la vigencia actual de esta narrativa (que analizo en Belinchón, 2020, en prensa), lo que creo que podría considerarse otro paralelismo reseñable entre el libro de Feinstein y las obras de Rivière es que todos estos textos traslucen un interés y gusto genuinos por la actividad misma de contar. Dejando también de lado el común interés de estos dos autores por la poesía (otra coincidencia más y otra forma diferente de 'contar'), ambos logran ofrecer relatos elaborados y muy personales que clarifican la génesis histórica de los conocimientos y de las prácticas en el campo del autismo y que obligan a revisar las creencias y actitudes previas (i. e., que cambian por sí mismos la historia). Los relatos de Feinstein y de Rivière aportan la voz de los pioneros y a la vez nos aportan su propia voz. Así, y como la comunicación humana tiene característicamente un formato dialógico, poder oír de nuevo sus voces (las de todos ellos) ofrece en cada relectura oportunidades de activar y de enriquecer nuestra propia voz.

Es quizá por la suma de estos paralelismos (y/o por otras sensaciones que aún no soy capaz de explicar) por lo que cada vez que releo esta Historia del Autismo. Conversaciones con los pioneros no puedo evitar imaginarme cómo habría disfrutado Rivière leyendo este libro. De haberse publicado unos años antes, estoy convencida de que habría querido traducirlo al español él mismo y de que, por supuesto, habría leído su versión original de un tirón y con la misma fruición que lo hice yo. También, estoy convencida de que él y Feinstein, como ambos hicieron en su momento por separado con Theo Peeters, habrían entablado una de esas amistades que duran siempre, porque combinan el mutuo afecto, el respeto, la admiración, un mismo tipo de humor y la íntima convicción de compartir los mismos valores y las mismas causas. Peeters fue un pionero belga fallecido en 2018 que participó en España en diversas acciones formativas (algunas organizadas por Rivière desde APNA) y cuyas contribuciones son muy apreciadas mundialmente. En su libro, Feinstein se refiere a él como "uno de los profesionales más empáticos de los que trabajan actualmente en el campo del autismo en todo el mundo", igual que, cuando se refiere a Rivière, lo describe como “un hombre sensible, lleno de compasión” (pp. 357 y 375, respectivamente, de la ed. esp.). Pienso también que, de hecho, al propio Feinstein, también, podrían aplicársele esos calificativos: sin lo que reflejan, la historia del autismo que él ha escrito no habría podido ser como es.

\section{Ecos de ayer y de hoy: reflexiones de Adam Feinstein y de Gerardo Herrera}

Historia del autismo. Conversaciones con los pioneros ha tenido críticas excelentes desde que se publicó la primera edición en inglés (2010) y ha provocado también múltiples reacciones, destacándose siempre que es un libro ciertamente imprescindible. 
La publicación original recibió encendidos elogios por parte de algunas de las figuras más destacadas en el campo del autismo, hasta el punto de que Simon Baron-Cohen, Theo Peeters, Darold Treffert, Donna Williams, Fred Volkmar, Gary Mesibov, Lorna Wing, Susan Folstein y Uta Frith escribieron comentarios subrayando la originalidad y calidad de la obra que se incluyeron en la portadilla o en las contraportadas, tanto de esa edición como de sus traducciones. Muchos libros y artículos posteriores citan ya este trabajo como un referente, y cada vez más monografías sobre historia del autismo han dado continuidad a algunos de los hilos narrativos planteados por Feinstein, aunque no siempre compartan sus tesis (p. e., Silberman, 2015; Dovan y Zucker, 2016; Robison, 2016; Czech, 2018, 2019; Zeldovich, 2018). En español, también los ecos de este libro de Feinstein se están visibilizando cada vez más en textos de diverso formato (ver p. e., Alonso, 2020; Belinchón, 2020, en prensa; Valdez, 2020, en prensa). Pero, ¿qué piensan ahora sobre este libro Adam Feinstein y Gerardo Herrera (respectivamente, autor del libro y editor de su versión en español)? ¿Cuál es su opinión actual sobre él?

En la edición en castellano (2016), además de añadirse una extensa Adenda sobre la historia del autismo en España (37 páginas), se ampliaron y modificaron varios pasajes del texto original. El ajuste vino obligado, en primer lugar, por el fallecimiento de varios de los pioneros y pioneras entrevistados en el libro, como fue luctuosamente el caso, entre otros, de Gerhard Bosch -a quien cité más arriba-; Lorna Wing, fallecida en 2014; Donna Williams, fallecida en 2017, o Sula Wolff -psiquiatra fallecida en 2009, nacida en Alemania pero afincada en Reino Unido tras la llegada de Hitler al poder, que en 1996 reivindicó con escaso éxito la figura pionera de Grunya Shukareva traduciendo el trabajo de esta al inglés (ver Wolff, 1996, 2004). En segundo lugar, el ajuste de ciertos pasajes de la edición en inglés del libro devino inevitable, toda vez que diversos estudios posteriores habían empezado a ofrecer datos e interpretaciones nuevos sobre algunos hechos y protagonistas descritos por Feinstein.

Desde la publicación de esta edición en español, la historia del autismo (como la historia en general) ha seguido un curso muy rápido, por lo que he considerado oportuno preguntar directamente al autor y al editor de la edición en español su valoración del texto original, del texto traducido y de aquellos eventos recientes en el campo del autismo que, en su opinión, han sido más relevantes. Transcribo a continuación ahora sus propias reflexiones y cierro con ellas estas páginas.

Pregunta 1. Han pasado ya 10 años desde la primera edición inglesa del libro, ¿qué diríais que aportaron esa edición y su traducción al español en su momento?

\section{A.F.:}

Mi libro fue, en sí mismo, un libro pionero. Soy la única persona que pudo hablar con casi todos los auténticos pioneros en la historia del autismo: entre ellos, Leon Eisenberg (el colega más cercano de Leo Kanner), Lorna Wing, Michael Rutter, Uta Frith, Simon Baron-Cohen, Isabelle Rapin, Margaret Bauman y Thomas Kemper, así como con la hija de Hans Asperger, el hijo de Kanner, etc., etc. 
Además, en mi viaje por el mundo pude trazar y aclarar algunos vínculos importantes (y a veces olvidados o muy poco conocidos). Por ejemplo, la influencia de la visita de Eric Schopler a la Escuela Sybil Elgar en Londres en su decisión de establecer TEACCH en Carolina del Norte. Aparte, por supuesto, del odio de Schopler por Bruno Bettelheim, con quien Schopler trabajó durante un tiempo en la Escuela Ortogénica de Chicago, cuando fue testigo horrorizado de la monstruosidad de Bettelheim, sobre todo su violencia física y verbal hacia los niños autistas en la escuela y la brutal estrategia de Bettelheim llamada 'parentectomía' (que impedía a los niños la presencia física y la influencia supuestamente 'malvada' de sus padres). Schopler decidió, muy al contrario, que uno de los aspectos cruciales de TEACCH sería la constante colaboración con los padres para que participaran en las terapias, en la educación y en el progreso de sus hijos.

\section{G.H.:}

De la edición en español, yo destacaría el esfuerzo importante que se hizo para documentar la historia del autismo en España y en otros países de habla hispana como Argentina, recopilando numerosos nuevos testimonios y enriqueciendo así las perspectivas recogidas sobre la historia del autismo en estos países.

Pregunta 2. ¿Del reconocimiento a qué datos, hechos o personas os sentís más orgullosos o satisfechos?

\section{A.F.:}

Estoy orgulloso de muchas cosas. De haber rescatado las voces de los pioneros. Podría citar muchos ejemplos memorables. Recuerdo con placer mis fascinantes charlas personales (y esclarecedoras, o a veces sorprendentemente enigmáticas) en Harvard con Leon Eisenberg sobre sus recuerdos de Kanner (profundizadas por mis múltiples intercambios de e-mails con él después gracias a su cordialidad y generosidad). Dos de las cosas más impactantes que admitió Eisenberg fueron su incapacidad de comprender la decisión de Kanner (en 1956) de abandonar el lenguaje como uno de los criterios clave del autismo y el misterio (para Eisenberg) de la falta de cualquier propuesta, por parte de Kanner, de una posible y específica etiología orgánica del autismo hasta después de 1971.

Descubrí las primeras pruebas (durante mi larga conversación con la hija de Hans Asperger, Maria Asperger Felder, en Zúrich) de que Asperger fue el auténtico pionero, y no Kanner. Mucha gente sigue hablando del artículo de Kanner de 1943 y luego del artículo de Asperger del año siguiente. Incluso quienes citan el discurso y artículo previos de Asperger (de 1938) no mencionan el hecho (¡porque todavía no han leído mi libro!) de que Asperger estaba utilizando el término 'autismo' a principios de los años 1930, es decir, más de una década antes que Kanner. 
También estoy orgulloso de haber extraído del gran Michael Rutter la franca admisión de que se había equivocado inicialmente (es decir, antes de su histórico estudio con Susan Folstein de 1977) cuando pensaba que era muy poco probable una etiología genética del autismo: “iTodos cometemos errores!”, me dijo Rutter.

Tuve la suerte de compartir una amistad enriquecedora con Lorna Wing durante veinte años o más. Siempre me impresionó su humildad frente a la complejidad del autismo. De hecho, recuerdo un comentario suyo mientras viajábamos juntos en tren de Londres a Manchester: “Todavía no sabemos lo que es el autismo”. Lorna también me confesó (y lo cito en mi libro) que siempre se arrepintió de no haber subrayado 'imaginación social' en su célebre tríada de alteraciones, en vez de 'imaginación' sin más. Y, por último, Wing me dijo que no le importaba si el DSM-5 eliminaba 'síndrome de Asperger' -término que ella misma había introducido en 1981-cuando se publicara esa edición del manual diagnóstico internacional9. "Las etiquetas no importan", me dijo. "Definir las necesidades precisas de cada individuo es lo que cuenta. Hay que pensar en términos dimensionales en lugar de categóricos”.

Otra declaración importante en mi libro: la de Uta Frith diciéndome que ella tenía que haber elegido una terminología menos negativa cuando introdujo su hipótesis neuropsicológica del autismo, que llamó 'coherencia central débil'. Hoy en día, Frith prefiere el término más positivo 'local processing bias' ('sesgo hacia el procesamiento local'), que indica que este estilo cognitivo diferente puede representar, a veces, una ventaja (por ejemplo, en el lugar del trabajo -ver más adelante-).

Fue muy útil trazar la evolución del concepto del autismo en países tan diferentes como China, Argentina, Etiopía, España e India, con anécdotas divertidas y, a veces, muy instructivas.

Y como crítico de cine, fue intrigante hablar con algunos de los asesores principales de Rain Man, que me revelaron que la película empezó con un guion muy diferente (¡ninguna mención al autismo y una temática que incluía una persecución automovilística del FBI!).

Por encima de todo, estoy orgulloso de haber revelado y enfatizado los detalles del indudable heroísmo de los padres como los auténticos pioneros en la lucha empedernida contra las dañinas ideas psicogénicas de Bruno Bettelheim.

\section{G.H.:}

Dentro de la Adenda sobre España, me siento especialmente orgulloso del trato que se le da a la figura de Ángel Rivière y a su papel en la historia del autismo en nuestro país, así como a los pioneros familiares de personas con autismo que fundaron el movimiento del autismo en España. También el reconocimiento a profesionales pioneros, como Ángel Díez Cuervo, y a su capacidad de ir contra corriente para minimizar el impacto de las teorías psicoanalíticas que vinculaban a las madres con el autismo de sus hijos, que en España tuvo muy corto recorrido gracias a ellos.

9 El DSM se publicó en 2013.

Ediciones Universidad de Salamanca / CC BY-NC-ND

Siglo Cero, vol. 52 (2), 2021, abril-junio, pp. 61-81 
Por otro lado, me siento también orgulloso de la celebración de la Jornada 'El autismo en España: Una mirada al futuro en clave de historia' celebrada el 9 de mayo de 2017 en la Facultad de Psicología de la UAM. Esa Jornada, organizada para presentar el libro de Adam, nos trajo de regalo un entrañable testimonio sobre el valioso y pionero trabajo de Jesusa Pertejo en los años 1950. El testimonio, aportado por su hija Margarita Alcamí Pertejo, psiquiatra infantil en el Hospital de La Paz de Madrid, nos reveló cantidad de detalles de la vida de esta gran mujer a la que no tuve la suerte de conocer en persona. La Adenda sobre la historia del autismo en España en la versión en lengua española del libro de Adam incluye varias páginas dedicadas a Jesusa Pertejo y suponen un reconocimiento muy necesario de su figura ${ }^{10}$.

\section{Pregunta 3: Contamos abora con otras publicaciones sobre la historia del autismo y sobre algunos de los pioneros. ¿Sentís que esos trabajos desautorizan o hacen necesario modificar algo?}

\section{A.F:}

¡Qué pregunta más apropiada y oportuna! Me parece que son tres los otros libros principales sobre la historia del autismo: NeuroTribes, de Steve Silberman; Unstrange Minds, de Roy Richard Grinker, e In a Different Key, de John Donvan y Caren Zucker. Ninguno de los tres, en mi opinión, demuestra la amplitud geográfica e histórica del mío. Además, tengo otros problemas con estos tres libros.

Estoy precisamente considerando la posibilidad de escribir una nueva edición de mi libro por muchas razones, pero en parte para aclarar y corregir algunos detalles que aparecen en Neurotribes. Déjame subrayar que Steve es amigo mío y que me gustan muchos aspectos de su libro, sobre todo el importante descubrimiento de que dos colegas austríacos de Hans Asperger (Georg Frankl y Anni Weiss) colaboraron con Leo Kanner en la Universidad Johns Hopkins de Baltimore, Estados Unidos. Tengo la impresión de que a Steve se le ocurrió la idea de investigar las relaciones entre Frankl, Weiss y Asperger tras leer un párrafo aislado en mi propio libro. Yo había hablado en Viena con un par de colegas más jóvenes de Asperger (Elizabeth Wurst y Maria Theresia Schubert), que me confirmaron (años antes de la publicación de Neurotribes) que dos colegas (sin nombrarlos) emigraron de Austria a Estados Unidos. Yo me tenía que haber lanzado a investigar esta impactante revelación en mi propio libro antes que Silberman, ipero supongo que yo ya estaba viajando a otro país y a otro tema! Mi otro problema con Neurotribes, así como con los otros dos libros que cité antes, de Grinker y de Donvan y Zucker, es que ninguna de las tres obras incluye

10 Pertejo, Rivière y la autora de estas páginas, pese a sus diferencias de edad, coincidieron varios cursos como profesores de la Facultad de Psicología de la Universidad Autónoma de Madrid (UAM), a principios de los años 80. Las aportaciones de los dos primeros fueron conjuntamente reconocidas de nuevo, un año después de la celebración de la Jornada a la que se refiere Gerardo Herrera, en la publicación institucional conmemorativa del 50 ${ }^{\circ}$ aniversario de la creación de esa universidad (ver Belinchón y Fernández-Ballesteros, 2018). 
entrevistas con los viejos pioneros. La ausencia de estos testimonios personales es llamativa.

\section{G.H.:}

De todo lo escrito acerca de la historia del autismo, se podría decir que el libro de Adam es el texto más completo y riguroso, por diferentes motivos. Por un lado, este libro refleja una diversidad de temas y dimensiones que han influido en el avance del conocimiento acerca del autismo y que, sin pretender ser exhaustiva, es realmente amplia y completa. Por otro lado, Feinstein aborda todos esos temas recogiendo de manera sistemática las diferentes perspectivas de las personas implicadas o pioneras, lo que dota al texto de mayor rigor y, además, lo hace muy ameno.

A día de hoy contamos con otros textos relevantes sobre la historia del autismo publicados también en lengua española (Silberman, 2019; Czech, 2019). Estos trabajos citan en numerosas ocasiones el trabajo de Adam Feinstein, basándose en su versión original en inglés y sirviéndose de su trabajo como una de las fuentes más relevantes. Es importante destacar que la versión española del trabajo de Feinstein (2016) ya incorporó entre sus novedades un adelanto de los datos que después publicaría Czech (2018) acerca de la posible implicación de Hans Asperger en el Tercer Reich. Una vez más, el trabajo riguroso de Feinstein, incorporando entrevistas a las personas autorizadas que cuentan con diferentes perspectivas sobre este asunto, lo hace más valioso y refleja la naturaleza poliédrica de unos hechos que solamente pueden entenderse en el contexto de la historia.

Pregunta 4. En la edición española, aparte de la obligada actualización de fechas y tiempos verbales, 'retocamos' frases referidas a Asperger y a Lovaas, ampliamos significativamente la sección dedicada a Argentina y añadimos la Adenda de la historia del autismo en España. En 2020, ¿creéis que abora habría que 'retocar' o ampliar algo más?

\section{A.F.:}

En cualquier nueva edición de mi libro, discutiría muy directa y profundamente la cuestión de la supuesta colaboración de Hans Asperger con los nazis. Las nuevas acusaciones contra Asperger arrancaron después de la publicación de la edición inglesa de mi libro en 2010, empezando con las investigaciones de Herwig Czech en Austria, luego seguidas por el libro de Edith Sheffer. Desde luego, algunos de los detalles revelados por Czech y Sheffer parecen condenatorios. Pero mucho más recientemente (en concreto, en 2019), he descubierto información adicional que pone en duda algunos elementos de las alegaciones de Czech y las suposiciones de Sheffer que necesito presentar, para matizar todo lo escrito sobre este tema tan importante. 


\section{G.H.:}

En relación con la Adenda sobre España, incidiría en la nueva página escrita en 2019 con la integración de FESPAU en la Confederación Autismo España ${ }^{11}$, fruto de un importante esfuerzo de convergencia por parte de ambas organizaciones. Ha logrado que el movimiento asociativo del autismo sea más fuerte y facilita la interlocución con el Gobierno. También se han producido otros avances importantes, como por ejemplo el hecho de que el Ministerio de Educación haya extendido el sistema de becas a todo el alumnado con trastorno del espectro del autismo, respondiendo así a una demanda histórica del movimiento asociativo del autismo. Con la nueva normativa, también acceden a estas becas los alumnos que no tengan un certificado de discapacidad (que se concede por una valoración de discapacidad superior al 33\%), que anteriormente estaban excluidos.

Pregunta 5: El último capítulo del libro dibuja lineas de desarrollo y debate en el campo del autismo para un futuro inmediato que abora es también pasado. ¿Cómo de exactas diríais que han resultado esas predicciones? ¿Qué destacaríais del devenir de estos últimos diez años?

A.F.:

Creo que la mezcla de optimismo y cautela en el último capítulo refleja bien la situación actual. A pesar de los grandes avances en algunas áreas, siguen las confusiones y los malentendidos sobre una condición tan compleja como es el autismo. Me parece que Donna Williams y Theo Peeters (ambos tristemente fallecidos después de la publicación de mi libro) tenían razón cuando sugirieron que la etiqueta de 'autismo' sigue suscitando reacciones lamentables de recelo, si no de estigma, en muchos países del mundo.

Pero yo soy optimista nato. En una segunda edición revisada de mi libro, yo daría más ejemplos positivos haciendo hincapié en lo que las personas con TEA pueden hacer, no en lo que no pueden hacer. Este fue el mensaje de mi libro más reciente, Autism Works, sobre autismo y empleo (publicado por Routledge en 2018): a saber, que el autismo puede constituir una ventaja en algunos casos en el lugar del trabajo. Me parece esencial demoler el modelo del autismo basado en los déficits (en vez de las fortalezas) que, por desgracia, sigue vigente en muchas partes del mundo.

\section{G.H.:}

A pesar de los grandes avances producidos en el conocimiento del autismo y también en el reconocimiento de sus necesidades y su inclusión social, destacaría el hecho

11 FESPAU y Autismo España son entidades sin ánimo de lucro de ámbito estatal, fundadas en 1994, que conjuntamente representan ahora a más de 130 asociaciones de familiares de personas con trastornos del espectro del autismo en nuestro país. 
de que para muchas personas con TEA aún existe una enorme falta de conocimiento y de eficacia de las intervenciones a ellas dirigidas, especialmente a las que cuentan con mayores dificultades y son más vulnerables.

Es cierto que cada vez se conocen mejor los factores que predicen un mejor o peor pronóstico en el autismo, pero incluso los programas de mayor respaldo científico parecen no ser tan efectivos para niños con TEA y múltiples comorbilidades, incluso si se ha empezado a trabajar con ellos desde bien pequeños.

\section{Pregunta 6: ¿ Hay alguna otra impresión, valoración o comentario que os gustaría ver recogidos en esta reseña?}

\section{A.F.:}

¡Creo que he dicho más que suficiente arriba! No obstante, quisiera añadir algo que me parece importante. En una segunda edición revisada de mi libro, incluiría más anécdotas personales de mi vida como padre de un hijo severamente autista, Johnny (de quien, dicho sea de paso, estamos muy orgullosos por su coraje en manejar la actual cuarentena en el Reino Unido, con su dramático cambio de rutina y estructura). Yo haría hincapié en las relaciones entre mis experiencias personales de vivir con un hijo autista con la evolución del concepto del autismo y las investigaciones científicas y educativas. También explicaría más específicamente cómo el acto de estudiar la historia del autismo es tan importante no solamente para entender esta condición tan enigmática y heterogénea (ique muchas veces comparo con el misterio de las duchas de hotel, tan diferentes una de la otra como un niño autista del otro!), sino para evitar los errores en el tratamiento práctico de individuos autistas. Por último, quisiera agradecerte a ti, Mercedes, tu magnífica traducción de mi libro al castellano y a Gerardo Herrera y Autismo Ávila haber publicado una edición tan hermosa.

\section{G.H.:}

Como editor y también en nombre de Autismo Ávila, simplemente agradeceros, Mercedes y Adam, vuestro compromiso infinito con el autismo y la dedicación de vuestro talento a esta noble causa.

\section{Referencias bibliográficas}

Alonso, J. R. (2020). Schopler y el TEACCH. Blog https://jralonso.es/2020/05/17/schoplery-el-teacch/\#more-325374

Bárcenas, R. (2002). Contexto de descubrimiento y contexto de justificación: un problema filosófico en la investigación científica. Acta Universitaria, 12(2), 48-57.

Belinchón, M. (2020, en prensa). Definición y explicación teórica del autismo: la narrativa de Ángel Rivière y sus reflejos. Infancia y Aprendizaje/Journal of Psychology and Education, $43 / 4$. 
Belinchón, M. y Fernández-Ballesteros, R. (2018). Tres nombres para la historia de la Facultad de Psicología de la UAM: Jesusa Pertejo, Isidoro Delclaux y Ángel Rivière. Revista Encuentros Multidisciplinares, 58 (n. ${ }^{\circ}$ extraordinario: "50 años de la UAM, Un homenaje multidisciplinar a sus grandes baluartes”). http://www.encuentros-multidisciplinares.org/ revista-58-59/mercedes-belinchon_rocio-fdez-ballesteros.pdf

Belinchón, M., Palomo, R. y Campos, R. (2020, en prensa). Miradas sobre el autismo en 2020: monografía homenaje a Ángel Rivière. Introducción. Infancia y Aprendizaje/Journal of Psychology and Education, 43(4).

Czech, H. (2018). Hans Asperger, National Socialism, and "race hygiene" in Nazi-era Vienna. Molecular Autism, 9-29.

Czech, H. (2019). Hans Asperger, autismo y Tercer Reich: en busca de la verdad histórica. NED ediciones.

Davidson, J. y Orsini, M. (Eds.). (2010). Worlds of autism. University of Minnesota Press.

Donvan, J. y Zucker, C. (2016). In a different key. The story of autism. Penguin Books.

Fletcher-Watson, S. y Happé, F. (2019). Autism. Routledge.

Grice, H. P. (1975). Logic and conversation. En P. Cole y J. L. Morgan (Eds.), Syntax and semantics, vol. 3: speech acts (pp. 41-58). Academic Press.

Grinker, R. R. (2007). Unstrange minds. Basic Books.

Kennym, L., Hattersley, C., Molins, B., Buckley, C., Povey, C. y Pellicano, E. (2016). Which terms should be used to describe autism? Perspectives from the UK autism community. Autism, 20(4), 442-462.

Lakoff, G. (2004). Don't think of an elephant: know your values, frame the debate. Chelsea Green Publishing (trad. esp., Editorial Complutense, 2006).

LAwson, W. y LAwson, B. (2017). Transitioning together: one couple's journey of gender and identity discovery. Jessica Kingsley Publ.

Matson, J. y LoVullo, S, (2009). Trends and topics in autism spectrum disorders research. Research in Autism Spectrum Disorders, 3, 252-257.

Muñoz Molina, A. (2012). Hilos narrativos. Tribuna en El Pais-Cultura, 18 febrero.

Nadesan, M. H. (2005). Constructing autism. Routledge.

O’Dell, L., Rosqvist, H., Ortega, F., Brownlow, Ch. y Orsini, M. (2016). Critical autism studies: exploring epistemic dialogues and intersections, challenging dominant understandings of autism. Disability and Society, 31(2), 166-179.

Reichenbach (1938/1952). Experience and prediction. University of Chicago Press.

Robison, J. E. (2016). Kanner, Asperger, and Frankl: a third man at the genesis of the autism diagnosis. Autism, 21(7), 862-871.

SHeffer, E. (2018). Asperger's children: the origins of autism in Nazi Vienna. W.W. Norton (trad. esp., Grupo Planeta, 2019).

Silberman, S. (2015). NeuroTribes. The legacy of autism and the future of neurodiversity. Avery (trad. esp., Ed. Ariel, 2016).

Sperber, D. y Wilson, D. (1986). Relevance: communication and cognition. Oxford: Blackwell (trad. esp., Ed. Visor, 1994).

VAldez, D. (2020, en prensa). Contextos amigables con el autismo. Hilos y colores de su entramado. Autismo Ávila.

Verdugo, M. Á., Canal, R., Sotillo, M., Morueco, M. y Tamarit, J. (2020). Ángel Rivière en el corazón y en la memoria de la psicología española y del autismo. Siglo Cero, 52(2), $7-42$. 
Verhoeff, B. (2012). What is this thing called autism? A critical analysis of the tenacious search for autism's essence. BioSocieties, 7(4), 410-432.

Verhoeff, B. (2013a). Autism in flux: a history of the concept from Leo Kanner to DSM-5. History of Psychiatry, 24(4) 442-458.

VerhoefF, B. (2013b). The autism puzzle: challenging a mechanistic model on conceptual and historical grounds. Philosophy, Ethics, and Humanities in Medicine, 8-17.

WhyATt, C. y Torres, E. (2018). Autism research: an objective quantitative review of progress and focus between 1994 and 2015. Frontiers in Psychology, vol. 9 (artíc. 1526), 1-18.

WolfF, S. (1996). The first account of the syndrome Asperger described? Eur Child Adolesc Psychiatry, 5, 119-132.

Wolff, S. (2004). The history of autism. Eur Child Adolesc Psychiatry, 13, 201-208.

Zeldovich, L. (2018). How history forgot the woman who defined autism. Spectrum, 7, noviembre. 


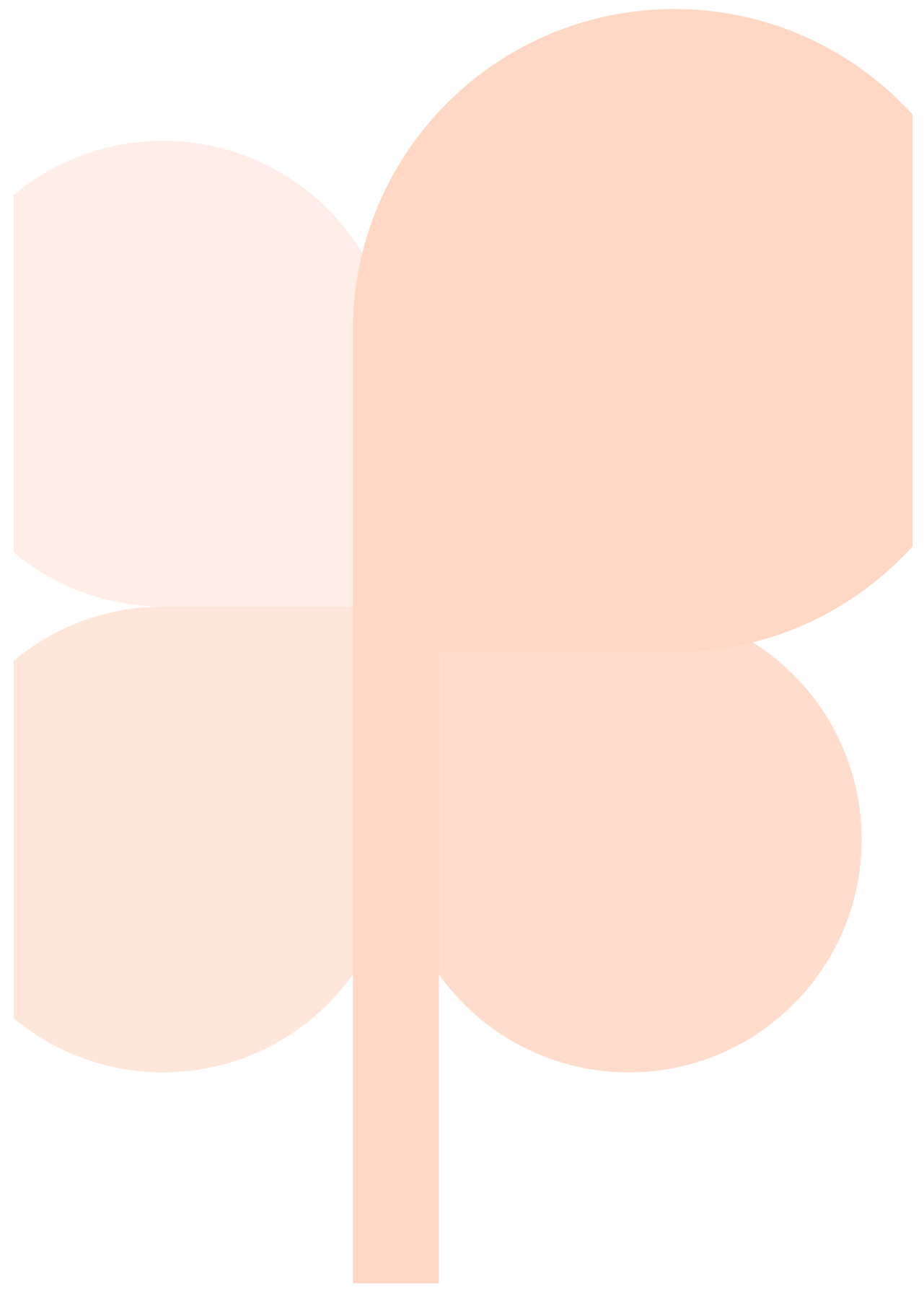

